\title{
BMJ Open Migrant families with children in Montreal, Canada and transnational family support: a protocol for a focused ethnography
}

\author{
Lisa Merry, ${ }^{1,2}$ Jill Hanley, ${ }^{2,3}$ Monica Ruiz-Casares, ${ }^{2,4}$ Isabelle Archambault, ${ }^{5}$ \\ Dominic Mogere ${ }^{6}$
}

To cite: Merry L, Hanley J, Ruiz-Casares M, et al. Migrant families with children in Montreal, Canada and transnational family support: a protocol for a focused ethnography. BMJ Open 2019;9:e029074. doi:10.1136/ bmjopen-2019-029074

- Prepublication history and additional material for this paper are available online. To view these files, please visit the journal online (http://dx.doi org/10.1136/bmjopen-2019029074).

Received 10 January 2019 Revised 29 July 2019 Accepted 06 September 2019

Check for updates

(c) Author(s) (or their employer(s)) 2019. Re-use permitted under CC BY-NC. No commercial re-use. See rights and permissions. Published by BMJ.

For numbered affiliations see end of article.

Correspondence to

Dr Lisa Merry;

lisa.merry@umontreal.ca

\section{ABSTRACT}

Introduction There is a gap in research regarding transnational family support (emotional, practical, spiritual, informational and financial) as a resource for migrant families with children. From the perspective of migrant families and their family back home, the objectives of this study are to (1) identify the types and ways that transnational family support is provided to migrant families in Canada; (2) assess for patterns in the data that may suggest variations in the nature of this support (eg, by migration status, time in Canada, children's ages, family circumstances) and over time and (3) explore the impact (positive and negative) in receiving and providing transnational support, respectively.

Methods and analysis A focused ethnography is planned. We will recruit 25-35 migrant families with children with different migration histories (eg, economic or forced migration from a mix of countries) and family circumstances (eg, single parenthood, families living with extended family, families with children in the home country) living in Montreal, Canada. Families will be recruited through community organisations. Data will be gathered via semistructured interviews. To capture the perspective of those providing support, family members in the home country for each migrant family will also be recruited and interviewed through communication technology (eg, WhatsApp). Data collection will also involve observation of 'transnational interactions' between family members in Montreal and those back home. Data will be thematically analysed and results reported in a narrative form with an in-depth description of each theme.

Ethics and dissemination Ethical approval was obtained from the sciences and health research ethics committee at the University of Montreal. Study results will be shared through traditional forums (publication, conference presentations) and via other knowledge dissemination/ exchange activities (eg, 'lunch and learn conferences' and seminars) through the research team's research centres and networks to reach front-line care-providers who interface directly with migrant families.

\section{INTRODUCTION}

Raising and caring for children in the context of resettlement poses a number of challenges and many migrant parents report feeling

\section{Strengths and limitations of this study}

- This study will generate new knowledge on transnational family support as a resource for migrant families with children, which is an area that has received limited attention.

- A significant strength of the study is that data will be gathered from migrant families in Canada and also from family members 'back home' to include the perspectives of those who are providing support from a distance.

- Additionally, the sample will be diverse and include migrant families with various migration histories, countries of origin, languages and lengths of time in Canada, and also different family circumstances. We will also seek to have a mix of family members (eg, parents, siblings; men and women) as participants from 'back home'.

- A limitation of the study is that participation from family back home requires access to technology so those who are poor or living in less resourced countries may not be able to participate.

- Another limitation is that participants may not feel comfortable sharing negative experiences in the presence of other family members.

overwhelmed and stressed. ${ }^{1-21}$ For migrants from low-and middle-income countries, and for those with more vulnerable or precarious statuses (eg, refugees, asylum seekers), difficulties appear to be amplified. ${ }^{22}$ Despite these challenges, migrant parents also report many sources of strength and resiliency. ${ }^{1} 1016$ 23-25 One important resource is the support provided by family in the home country. ${ }^{22}$

There is a growing interest on the impact of migration on families and in transnational research as it is recognised that migration affects the whole family, including those who remain in the home country. ${ }^{26}$ 'Transnational family support' for migrant families with children is an understudied phenomenon 
and few studies have included the perspectives of family members who are providing support from a distance. The objective of this study is to explore the experiences of migrant families in Canada and their family members back home in receiving and providing transnational support, respectively.

\section{Migration and families with children in Montreal, Canada}

In 2017, Canada resettled more than 200000 economic and family-sponsored immigrants and over 35000 refugees and protected persons; one-fifth live in the province of Quebec. ${ }^{27}$ More than 41000 asylum claims were also made, half in Quebec.$^{28}$ Recent top source countries for Quebec include Algeria, China, Côte-d'Ivoire, France, Haiti, India, Iran, Mexico, Philippines and Syria. ${ }^{27,28}$ Montreal, a major urban centre in Quebec, is the main destination.

A number of migrants move with their spouses and children-approximately $20 \%$ of migrants are children less than 15 years old. ${ }^{27}$ For those who do not migrate with dependents, many are of reproductive age and have children after their arrival. Nationally, births to migrants account for up to $20 \%$ of births; in Montreal, where there is a higher density of migrants, the percentage exceeds greater than $50 \% .{ }^{29}$ About $35 \%$ of Canadian families with children have at least one migrant parent. ${ }^{30}$

Children are often central to migrants' decision to migrate, and the education, health and future of their children are of the utmost importance ${ }^{4}{ }^{8}$ Loss of social support networks, experiences of discrimination and racism, a lack of employment and housing, a shift in social status, adapting to a new culture and language, and barriers in accessing education, health and social services, however, can have important effects on the well-being of migrant parents and their children. ${ }^{41231-44}$ Parents face financial constraints, are preoccupied with work and therefore have insufficient time and money for raising their children. ${ }^{4544}$ A lack of affordable housing and living in less privileged neighbourhoods raises parents' concerns about their children's immediate safety, and about their ability to achieve upward mobility for themselves and their children, over the long term. ${ }^{83}$ Parents also worry about 'negative influences', feel they are losing authority, and fear that their children will lose their culture, language and attachment to their roots. ${ }^{412}$ 12-33 35-37 3944 Cultural and linguistic divides may cause tension between parents and children. ${ }^{31-3436}$ 45-47 Parents also face navigating unfamiliar systems, including schools, healthcare and child welfare, and must adapt to different parenting values and ways of socialising children. ${ }^{4832} 353738414248-51$

For children and youth, many struggle to reconcile the cultural differences and have to cope with intergenerational conflict, stigmatisation and sometimes violence. ${ }^{12}{ }^{52-55}$ Some also have to adapt to a new school structure (teaching styles and expectations) and often, learning in a new language.$^{5355}$ For those living in poverty and low-resource neighbourhoods, overcrowding and exposure to gangs and crime can be stressful. ${ }^{556}$ Shifting family roles and taking-on new responsibilities (eg, acting as interpreters for parents) can also cause strain. ${ }^{557}$ And for those who experienced trauma, refugee children in particular, this can result in mental health issues and behavioural problems ${ }^{56}$ In this context, migrant families need and access various sources of support.

\section{Transnational family support}

There is an extensive body of literature on transnational families and support across borders which mostly focuses on migrants sending remittances, distance parenting and caring for elderly parents back home. ${ }^{58-66}$ Research on transnational family support from the home country towards those who migrated is very limited. The few existing studies suggest that family members in the home country give support primarily in the form of emotional support but also provide practical help as well. ${ }^{67-70}$ For family members back home, some feel the support giving is unidirectional and strenuous, whereas others feel it is two-way and mutually beneficial. ${ }^{59}$ Some studies have also examined the experiences of female family kin who provided support to migrant families by caring for their children who remained in the home country. ${ }^{71}$ Although driven by a strong sense of obligation, difficulties including financial strain and emotional stress related to negotiating decision-making with migrant parents, sometimes arise. ${ }^{71}$ Overall, research on the impact on those back home who are providing support from a distance continues to be inadequate.

For migrant families, studies tend to focus on their experience of providing support towards the home country. ${ }^{59-62} 6566$ No studies explicitly examining transnational family support for migrant families with children living in a new country were identified. A recent qualitative literature review describing the parenthood experiences of refugees, asylum seekers and undocumented migrants, however, suggests families may receive transnational family support in multiple ways. ${ }^{22}$ This includes receiving parenting advice on a range of topics (nutrition, socialisation and discipline), emotional support, assistance to resolve family conflicts and help to maintain cultural traditions and language. This support may be provided directly by virtual communication with their family back home or indirectly through the contacts (religious groups, organisations or personal connections) that the family back home have in the receiving-country. Transnational family support may also be in the form of helping migrant families to access resources and maintain their engagement in various activities back home, and by caring for children and/or other family who remained behind. $^{2} 412157273$ Grandparents also sometimes visit to assist with childcare or children return to the home country temporarily to be cared for by family members there. ${ }^{64} 74$ Migrant families' experiences in receiving transnational family support appear to be positive (eg, feeling cared for $)^{70}$ as well as challenging (eg, feeling guilty, indebted ${ }^{75}$; however, the topic remains relatively unexplored. 


\section{Transnational perspective}

The health and well-being of migrants is a priority issue, and the inter-connectedness of families and countries, economically, socially, politically and in other spheres such as health, has given rise for receiving-countries, including Canada, to also be concerned about the impacts of migration on sending nations. ${ }^{26} \mathrm{~A}$ receiving-country centric approach has also been critiqued for its lack of consideration for the broader socio-cultural context that contributes to the identities, processes and experiences of migrants in their new countries. A 'transnational perspective' recognises that migrants' experiences are affected by the relationships that they maintain with family and friends, and by their continued engagement and attachment to their home country. ${ }^{76}$ It also acknowledges that the society and family in the home country are affected by migration and that there is continual interdependence between families across countries. ${ }^{77}$ For research, it implies considering the transnational aspects of migrants' lives and also doing cross-country research to better understand how transnational processes and practices shape the social and lived experiences of migrants. ${ }^{76} 77$

The concept of transnationalism has long been considered in the fields of sociology and anthropology, ${ }^{77}$ whereas in health and social care (eg, nursing, psycho-education, social work) it has largely been absent. There is, however, an emerging movement towards the use of frameworks that consider space, time and mobility across countries, to better understand the complexity of factors and experiences shaping migrants' health and well-being. ${ }^{78}$ In particular, 'transnationalism' has been shown to have important effects, both positive and negative, on mental health. ${ }^{80-83}$ Other research has also begun to explore the concept of transnationalism in care, including the use of services across borders, addressing transnational experiences in therapy (eg, distress related to separations and reunions and distance parenting of children left behind, cultural tensions between parents and adolescents) and family counsellors encouraging transnational ties to develop social and economic capital and to cope with losses. ${ }^{84} 85$ This research suggests that an overemphasis on integration or assimilation may have negative effects, ${ }^{86}$ whereas an approach in care that acknowledges migrants' transnational contexts, addresses concerns and reinforces supports that extend across countries may foster resiliency and a positive identity and give meaning and coherence to their lived experiences in the new country. ${ }^{87} 88$

Social support has also been established to be a key factor in migrant families' well-being and coping with the multiple stresses they face living in a new country. ${ }^{89-92}$ Informal support, families' personal contacts and resources via their networks of friends and family members have been identified as primary sources of help. ${ }^{89}$ There are many advantages to informal supports, including increased trust, mutual understanding, continuity and reciprocity. Empowering migrants by promoting and strengthening their informal support networks is therefore an important intervention for care-providers working with these families. ${ }^{89}$ This includes identifying and mobilising resources, optimising positive exchanges and mitigating harmful effects of negative relationships. ${ }^{89} 93$ Transnational family ties have been shown to be associated with social support among migrants ${ }^{80}$; however, it remains understudied and little is known on how it can be optimised as an informal support. To develop more responsive and socially responsible care for migrant families with children and their family back home, research is needed to better understand how transnational family support is a resource for migrant families and how it impacts families including those back home.

\section{Conducting research transnationally}

Transnational studies remain limited and thus far have mostly involved doing research with families across only two countries (ie, the migration and home countries) with travel across the sites to collect data. ${ }^{754-96}$ However, studies that include migrants and their families from a mix of countries can offer a diversity of perspectives and experiences. To make this feasible, new methods to gather data across multiple sites are therefore needed. ${ }^{9798}$ We recently conducted a small pilot study in Kisumu, Kenya to determine the feasibility of collecting data from 'family back home' using communication technology (ie, phone or internet). ${ }^{99}$ Nine family members who self-identified as providing support to migrant family members living in another country participated. Participants were interviewed by a researcher in Canada using Skype phone calls. Results showed that families back home were interested and willing to share their experiences and that collecting data from a distance via communication technology is feasible. The current study will build from this feasibility project and advance the methodological literature regarding the conduct of transnational research with migrants and their families living abroad.

\section{Research objectives}

From the perspective of migrant families and their family back home, the objectives of this study are to (1) identify the types and ways that transnational family support is provided to migrant families in Canada; (2) assess for patterns in the data that may suggest variations in the nature of this support (eg, by migration status, time in Canada, children's ages, family circumstances) and over time and (3) explore the impact (gains and challenges practically and psychologically) in receiving and providing transnational support, respectively.

\section{METHODS AND ANALYSIS \\ Overview}

This study will be carried out over a 2-year period. A focused ethnography will be used given the intent is to gather data on one selected element of an experience (transnational family support) of a specific group (migrants) and also due to the short, purposeful and intense nature of the data collection methods. ${ }^{100} 101$ The 
ethnographic approach, which involves documenting and qualitatively capturing social phenomena in its natural context using various methods and sources, is also considered well suited for studies examining transnational ties and processes. ${ }^{59} 77$ Migrant families with children living in Montreal, who self-identify as receiving transnational family support, will be recruited. 'Support' may include emotional, instrumental, financial and/or material help, as well as providing advice and/or information. ${ }^{89}$ Data will be collected through semistructured interviews and participant observation. Family back home will be recruited via the migrant families, and for these participants data will be gathered virtually. Data will be thematically analysed.

\section{Patient and public involvement}

The research questions for this study were developed based on a synthesis of the recent qualitative literature on the parenthood experiences of refugees, asylum seekers and undocumented migrants (from the perspectives of those raising and caring for children in a new country). ${ }^{22}$ The design and methods for the study were informed by the research team's previous experiences in conducting research with migrants, which included seeking community feedback. The Kenyan feasibility study informed the data collection methods for the participants 'back home', and we will also seek guidance from the community organisations as recruitment and data collection progress. The families participating in this study will help direct and shape the methods as well, including recruitment and data collection. The migrant families will assist in recruiting their family members back home and all interviews and observations will be adapted based on what participants are interested in and willing to share with the research team. All participants (migrant families as well those back home) will be asked if they would like to receive a brief summary of the results once the study is completed. Research assistants (RAs) will call those participants who request the summary, and will give a verbal report in the family's language. A written summary in English and French will also be provided to participants who wish to have it (electronic versions will be available for those back home).

\section{Recruitment}

Migrant families with children $(n=25-35)$ with different migration histories (eg, economic, family sponsored or forced migration, from a mix of countries, languages and lengths of time in Canada) and family circumstances (eg, different ages of children, children who migrated and children born in Canada, single parenthood, families with extended family members living with them, children who remained in home country) will be recruited. To be included migrant families must have at least one child (baby, young child, adolescent or youth) living with the family in Canada; having only adult children will not be sufficient for inclusion. Language will be an exclusion criteria if we are unable to accommodate a language. To minimise this exclusion, RAs who speak the most common languages (Arabic, English, French, Haitian Creole and Spanish) of more recently arrived refugees and asylum seekers will be hired; immigrants usually speak English or French since language ability is one of the eligibility criteria for immigrating to Canada. Interpreters will also be used as needed. Families will be recruited through community organisations in Montreal that provide services to migrant families with children. A list of potential organisations was provided through the Quebec umbrella organisation which acts as an association of the various groups, institutions and organisations working with immigrants, refugees and other migrants across the province. Depending on their availability and interest, we will identify a handful of these organisations to work with. We will recruit until data sufficiency is achieved (ie, until no new information is apparent).

Recruitment strategies (eg, posters, referrals, direct recruitment) will be co-developed and adapted to each organisation. Snowball sampling will also be used if recruitment through organisations is less successful. Families will call a RA (designated by language) or a RA will call/discuss in person (if referral or face-to-face recruitment) to explain the study, confirm eligibility and obtain verbal consent. Eligibility will be determined using a brief questionnaire. If a family agrees to participate, an interview time will be set and contact information will be collected. Consent will be re-confirmed and a form signed at the first meeting. Verbal consent will be accepted for anyone who does not feel comfortable signing the form. We will invite and encourage a mix of family members (mothers, fathers, extended family, children) to participate; however, the family will decide who participates. Consent/assent will be obtained from each individual; for a child under the age of 18 years to participate, a parent must consent and the child must also give their assent. Consent will be re-confirmed verbally at each contact. Family members who participate at subsequent contacts will sign a form when they join the study.

'Family back home' will be recruited via the migrant families. Migrant families will be asked to identify family (eg, siblings, spouses, grandparents, aunts, uncles, cousins) who they see as providing support to them. Attempts will be made to identify a mix of family members (across the different migrant families) to gather a range of perspectives. Migrant families will be asked to speak with their family back home to confirm their interest and willingness to participate in an interview. The migrant families will be given a brief information sheet that they can use to help them when speaking to their families. An interview time will then be set up. The study will be re-explained to the family back home and consent confirmed at the time of the interview. Electronic copies or pictures of the consent forms will be forwarded (by email, WhatsApp) for reference. For feasibility purposes, only verbal consent will be obtained from family members back home. The RA and a witness (a migrant family member or another RA) will sign the consent forms. Consents will be re-confirmed 
verbally at all subsequent contacts (if any). The consent process will also be completed for any new family participants that join at a later encounter. If family back home do not wish to participate, data will only be gathered from the migrant family members.

\section{Data collection}

Data collection will include interviews and observation of 'transnational interactions' between family members. Two to five contacts will be planned per family for a total of 2-5 hours of interview/observation data (for a total maximum of 175 hours). The first interview will be with the migrant family only. The interview will take place in the family's home or in another location if preferred (eg, at the university). Family members will participate together if more than one family member is participating; individual time will be accommodated if any family member, including children, wish to share some information privately (ie, individual time will be offered but not required). An interview guide will be used to stimulate discussion (see online supplementary appendix 1). Questions are open ended and participants will be asked to describe their family, migration (eg, economic/forced migration), and their family back home and how they maintain contact with them (frequency and how). They will then be asked to discuss in what ways their family back home provides support (with examples), share their feelings on how this experience is for them (positive and negative points) and explain how it is changed (or not) over time.

The second interview will be held with the migrant family and their family back home using WhatsApp (or skype, facetime, phone). This interview will be semistructured (the interview guide was pilot tested in the Kenyan feasibility study) (see online supplementary appendix 2). The family back home will be asked to introduce themselves, explain how they are 'related' to the migrant family and discuss the experience of their family moving away. They will then be asked to share their experiences of providing support, including types of support given (with examples), changes over time and their feelings about this experience (what is challenging, what is positive). The migrant families' presence will be necessary to ensure we are successful in connecting with the family back home (the family back home may not trust a stranger calling) and for continuing to build trust with the migrant family. They will be encouraged to engage in the discussion as much as they want. This group interview will also provide an opportunity to begin to observe the families' transnational interactions. Observational notes will be taken to document the family dynamics and non-verbal reactions and behaviours related to support. Interviews will be conducted by the RAs in the families' languages and audio-recorded if consent by everyone present is provided, otherwise only detailed notes will be taken.

One to three additional contacts (based on availability/ interest) will be set up to have more informal discussions and to further observe the families (see online supplementary appendix 3 ). We will ask if we can have another joint call with the migrant family and their family back home. We will also request to have at least one meeting with just the family back home. At these additional encounters, we will ask the families to 'show' us some examples of how they maintain contact (texts, Facebook/Instagram posts, emails, letters). These will be used to stimulate discussion, and if permitted will be 'observed' for content related to providing/receiving support. These contacts will also serve to explore points raised in earlier interviews more in depth and to validate our understandings/interpretations from the initial interviews. If we interview family members back home without the presence of their Canadian family members, we will also ask if there is anything they would like to share with us that they did not feel comfortable disclosing in earlier interviews.

Basic demographic information (eg, marital status, migration status of parents, education level of parents, family income) will be collected from the migrant families. Contextual data will also be gathered via field notes and memos (see online supplementary appendix 4).

\section{Analysis}

All interview data will be transcribed and translated to English (by the RAs) for analysis. Debriefing sessions with the RAs and field notes will be used to give context in order to optimise the interpretation and understanding of the translated interviews. ${ }^{102}$ Data from all sources (interviews, observations, and field notes) will be analysed together using qualitative analysis software. Analysis will be iterative and done throughout the data collection period. The data will be thematically analysed. ${ }^{103} 104$ First steps will involve reading and becoming immersed to 'get a feel' for the data, and to form initial impressions. The analysis will then involve line-by-line coding including inductive (open coding) as well as deductive coding (selective coding to address the specific study objectives). A selection of data will be independently coded by two members of the research team to assess inter-rater reliability. Data segments representing the various codes will be extracted and compared across different characteristics of families; we will also look for contrasts within families (within and between family members in Canada and those back home) and patterns over time. Gains and challenges will also be compared across types of support. Codes will then be organised into categories and then broader themes. ${ }^{103}$ All team members will review and confirm the final themes via consensus. Results will be written-up in a narrative form with an in-depth description of each respective theme. ${ }^{105}$ Basic demographics will be summarised.

\section{Rigour}

Trustworthiness will be enhanced by meeting families more than once, spending time with them in their homes and gathering data through different methods. ${ }^{106} 107$ Data quality will also be strengthened via ongoing validation 
with participants as data collection progresses. A systematic approach for analysis and rich descriptions (themes and context) and supportive quotes will be evidence of credibility. ${ }^{107}$ Gathering data from families with different experiences and circumstances will augment transferability of the findings. Team debriefings, including the RAs, will be used to discuss various interpretations of the data to minimise biases. Throughout recruitment and data collection, the RAs will be asked to reflect on and document their feelings and reactions during these processes and interactions with the families. ${ }^{101}$ Team meetings will also be used to maintain a reflexive stanceto exchange on our predispositions and to reflect on how we may be influencing the data collection and analysis. A detailed audit trail of data collection and analysis will be maintained.

Despite the rigorous methods, we acknowledge that we may have a select sample since we will be recruiting through only a few community organisations and snowball sampling, and families will be the ones to decide on which family members (locally and abroad) participate. There may also be some language barriers during recruitment, and the requirement to have access to technology may prevent the participation of some families. Families may also be selective in what they share and may not be as open regarding 'undesirable' experiences, especially the family back home who may feel uncomfortable saying anything negative in front of their family members in Canada. Likewise, children may also be hesitant to share their views in front of their parents and extended family. Working across different languages may also result in the misinterpretation and/or the misunderstanding of information. The analysis and presentation of findings will be conducted with these limitations in mind.

\section{ETHICS AND DISSEMINATION}

A number of safeguard measures will be put in place to ensure respect and safety of the migrant families and their family members back home. All participants will be asked to provide consent/assent before participating. Audio-recording will only be done if all individuals present during the interviews consent to it (consent for audio-recording will be documented on the consent forms separate from consent to participate). The consent form will be given to participants to read and will also be reviewed verbally (an electronic version will be sent to 'distant participants'). Participants will be given an opportunity to ask questions. Ongoing consent will also be sought during the interviews/observations and at each contact to ensure participants continue to feel comfortable in participating. Recruitment and data collection will be done in the language of the families by RAs who speak the language and as much as possible, with translated consent forms (translation will be for the most common languages; interpretation will be used as needed).

Recruitment and data collection will be conducted by RAs who will be trained and supervised by the research team. This will include reviewing the recruitment and data collection processes and discussing challenges (methodological as well as ethical) that may arise during recruitment and data collection and how to deal with these. RAs will also receive ongoing feedback on their interviews and field notes. We will hire RAs with a background in nursing, social work or a related field and who have work or other experience with populations living in vulnerable contexts (migrants or other). The RAs will be required to sign confidentiality agreements. To ensure the safety of RAs during home visits, they will advise at least one member of the research team on when and where they are going to conduct an interview. Safety tips will also be discussed during training (eg, knowing and studying the environment they are visiting; having a means to quickly and easily contact someone if there is an emergency; trusting their instincts). LM will be available to exchange with RAs as needed and team meetings will also serve as a forum to share emotions that may be evoked by the study.

All data (audio-recordings, transcripts, observational notes, field notes), memos and forms will be kept confidential-no names will be attached to the data and identification codes will be assigned and used. Participants will be told that information shared in the interviews should remain confidential. They will be advised, however, that we cannot guarantee this since as researchers, we have no control over what participants do once the interview is completed. All electronic data will be stored on the University of Montreal safe-drive. Electronic data will also be password encrypted and no names will be stored electronically. The consent forms (which include names and contact information), the hand-written and/or printed data and audio-recordings will be stored and locked in LM's university office. The list that links the families to the identification codes will also be kept in LM's office and kept separate from consent forms and data. Only the research team will have access to the data.

Data and consent forms will be kept for a minimum of 7 years after publication of the results according to the policy and procedures of the research ethics' board at the University of Montreal. Electronic data will be deleted, audio-recordings will be deleted or destroyed and paper data will be shredded. Shredded paper and tapes will be securely disposed of at LM's university.

No individual names or personal identifying information will be revealed in any summaries of the data, reports, publications or presentations resulting from this study. All findings will be reported without identifiers. If quotes are reported, personal identifiers (eg, name) will be removed and replaced with more general terms (eg, "my sister"). To avoid confidentiality issues, preference will be given to quotes without personal identifiers.

There are no direct or immediate gains for the participants, nor are there any foreseen harms. Migrant families will be compensated for their time. While it is hoped that the discussions may provide some validation to participants' experiences, some may feel sad or uncomfortable sharing their personal stories, migration experiences or 
struggles and conflicts within their families. Participants will be reminded that they are not required to answer any questions that they do not wish to answer and that they may withdraw their participation and/or data at any time. The RAs will remain attentive and cautious to not cause distress. For children and youth, we will follow their lead and let them participate and share as much as they feel comfortable. To make sure young participants are comfortable, RAs will adapt their language, will speak at the level of the children and will pay attention for non-verbal cues that may indicate a child does not want to answer or continue participating (this will be discussed during RA training). ${ }^{108}$ In the case where participants seem upset, RAs will offer to spend additional time with the families (including those online). A member of the research team will also be available to meet with any families that are distressed (by phone or in person for those in Montreal) to offer emotional support as needed. For migrant families, referrals to community organisations will be offered on an as-needed basis (if requested or if deemed urgent).

The findings from this study have relevance to academics and front-line workers who interface directly with migrant families with children. The results will be used to raise awareness regarding the transnational contexts and their effects on migrant families. They will also be used to stimulate discussion on best methods for conducting transnational research and to plan future studies on transnational support for migrants. To ensure the results reach the targeted audiences, we will disseminate through multiple forums. Three peer-reviewed articles are planned: (1) the main findings based on research questions; (2) an exploration of the impact of transnational family support on children/adolescents and (3) methodological and ethical strengths, challenges and solutions in gathering transnational data using communication technology from 'families back home'. To optimise the visibility of our publications, they will be made available via our online profiles, including ResearchGate and by circulation through social media (Twitter). Results will also be presented at conferences (local, national and international) where migrant and/or population health is a theme. Since the findings have implications for professional practice (nursing, social work, psycho-education, psychiatry), we will disseminate the findings through SHERPA, a research and training centre where three of us (LM, JH and MRC) are affiliated. SHERPA is the University Institute with regard to cultural communities of the Integrated University Health and Social Services Network for West-Central Montreal and has a vast network of researchers and front-line care-providers and holds a range of training and continuing education activities including 'brown bag sessions', seminars and colloquiums. We will also share the findings with the community organisations that supported recruitment. The team also has other affiliations/networks where results can be presented in seminars, research days and newsletters. To reach those in training, we will seek to present the results at a training workshop/summer school. As professors in health and social sciences, we will also sensitise our students to the results through courses and supervision of our graduate students. Participants will also receive a summary of the results in their language.

\section{Author affiliations}

${ }^{1}$ Faculty of Nursing, University of Montreal, Montreal, Québec, Canada

${ }^{2}$ SHERPA Research Centre, CIUSSS du centre-ouest-de-l'île-de-Montréal, Montreal, Québec, Canada

${ }^{3}$ School of Social Work, McGill University, Montreal, Québec, Canada

${ }^{4}$ Division of Social and Cultural Psychiatry, McGill University, Montreal, Québec, Canada

${ }^{5}$ School of Psychoeducation, University of Montreal, Montreal, Québec, Canada

${ }^{6}$ School of Public Health, Mount Kenya University, Thika, Kenya

Contributors LM conceived the idea of the study and drafted the protocol. $\mathrm{JH}$, MRC, IA and DM contributed to the conceptualisation of the study and critically revised the protocol for intellectual content. All authors read and approved the final manuscript.

Funding This research is being supported by an Insight Development Grant from the Social Sciences and Humanities Research Council (430-2018-00198).

Competing interests None declared.

Patient consent for publication Not required.

Ethics approval Ethical approval was obtained from the sciences and health ethics committee at the University of Montreal, the principal investigator's (LM) home institution.

Provenance and peer review Not commissioned; externally peer reviewed.

Open access This is an open access article distributed in accordance with the Creative Commons Attribution Non Commercial (CC BY-NC 4.0) license, which permits others to distribute, remix, adapt, build upon this work non-commercially, and license their derivative works on different terms, provided the original work is properly cited, appropriate credit is given, any changes made indicated, and the use is non-commercial. See: http://creativecommons.org/licenses/by-nc/4.0/.

\section{REFERENCES}

1. Busch Nsonwu M, Busch-Armendariz N, Cook Heffron L, et al. Marital and familial strengths and needs: refugees speak out. Journal of Ethnic And Cultural Diversity in Social Work 2013;22:129-44.

2. Lenette C, Brough M, Cox L. Everyday resilience: narratives of single refugee women with children. Qualitative Social Work: Research and Practice 2013;12:637-53.

3. Bowie BH, Wojnar D, Isaak A. Somali families' experiences of parenting in the United States. West J Nurs Res 2017;39:273-89.

4. Este DC, Tachble A. Fatherhood in the Canadian context: perceptions and experiences of Sudanese refugee men. Sex Roles 2009;60:456-66.

5. Liamputtong P. Motherhood and "Moral Career": Discourses of Good Motherhood Among Southeast Asian Immigrant Women in Australia. Qual Sociol 2006;29:25-53.

6. Ogbu HU, Brady B, Kinlen L. Parenting in direct provision: parents' perspectives regarding stresses and supports. Child Care in Practice 2014;20:256-69.

7. Valdez CR, Padilla B, Valentine JL. Consequences of Arizona's Immigration Policy on Social Capital Among Mexican Mothers With Unauthorized Immigration Status. Hisp J Behav Sci 2013;35:303-22.

8. Dumbrill GC. Your policies, our children: messages from refugee parents to child welfare workers and policymakers. Child Welfare 2009;88:145-68.

9. Vesely CK. Low-income African and Latina immigrant mothers' selection of early childhood care and education (ECCE): Considering the complexity of cultural and structural influences. Early Child Res Q 2013;28:470-86.

10. Ramsden R, Taket A. Social capital and Somali families in Australia Journal of International Migration and Integration 2013;14:99-117.

11. Tingvold L, Hauff E, Allen J, et al. Seeking balance between the past and the present: Vietnamese refugee parenting practices and adolescent well-being. Int J Intercult Relat 2012;36:563-74. 
12. Carranza ME. Building resilience and resistance against racism and discrimination among Salvadorian female youth in Canada. Child Fam Soc Work 2007;12:390-8.

13. Atwell R, Gifford SM, McDonald-Wilmsen B. Resettled Refugee Families and Their Children's Futures: Coherence, Hope and Support. J Comp Fam Stud 2009;40:677-97.

14. Ayon C. Service needs among Latino immigrant families: implications for social work practice. Soc Work 2014;59:13-23.

15. Bacallao ML, Smokowski PR. Entre DOS mundos/between two worlds: bicultural development in context. J Prim Prev 2009;30:421-51.

16. Betancourt TS, Abdi S, Ito BS, et al. We left one war and came to another: resource loss, acculturative stress, and caregiver-child relationships in Somali refugee families. Cultur Divers Ethnic Minor Psychol 2015;21:114-25.

17. Bonizzoni P. Immigrant working mothers reconciling work and childcare: the experience of Latin American and eastern European women in Milan. Soc Polit 2014:21:194-217.

18. Earner I. Immigrant families and public child welfare: barriers to services and approaches for change. Child Welfare 2007;86:63-91.

19. Jimenez-Castellanos $O$, Gonzalez G. Understanding the impact of micro-aggressions on the engagement of undocumented Latino mmigrant fathers: debunking deficit thinking. Journal of Latinos and Education 2012;11:204-17.

20. Leidy MS, Guerra NG, Toro RI. Positive parenting, family cohesion, and child social competence among immigrant Latino families. $J$ Fam Psychol 2010;24:252-60.

21. Lewig K, Arney F, Salveron M. Challenges to parenting in a new culture: implications for child and family welfare. (special issue: child welfare and the challenge of the new Americans). Evaluation and Program Planning 2010;33:324-32.

22. Merry L, Pelaez S, Edwards NC. Refugees, asylum-seekers and undocumented migrants and the experience of parenthood: a synthesis of the qualitative literature. Global Health 2017;13.

23. Vervliet M, De Mol J, Broekaert E, et al. 'That I live, that's because of her': intersectionality as framework for unaccompanied refugee mothers. Br J Soc Work 2014;44:2023-41.

24. Gagnon AJ, Carnevale F, Mehta P, et al. Developing population interventions with migrant women for maternal-child health: a focused ethnography. BMC Public Health 2013;13:471

25. Doucet $F . R e)$ Constructing home and school: Immigrant parents, agency, and the (Un)desirability of bridging multiple worlds. Teachers College Record 2011;113:2705-38.

26. International Organization for Migration (IOM). International dialogue on migration 2014. human mobility and development: emerging trends and new opportunities for partnerships, Intersessional workshop on migration and families. summary of discussions, 2014

27. Immigration Refugees and Citizenship Canada. Permanent residents - monthly IRCC updates. government of Canada. Available: http://open.canada.ca/data/en/dataset/f7e5498e0ad8-4417-85c9-9b8aff9b9eda?_ga=2.98559131.582204194 1513616346-640053866.1503087394

28. Immigration Refugees and Citizenship Canada. Asylum claimants - monthly IRCC updates. government of Canada. Available: http://open.canada.ca/data/en/dataset/b6cbcf4d-f763-4924a2fb-8cc4a06e3de4? ga=2.139830455.582204194.1513616346640053866.1503087394

29. Institut de la Statistique Quebec. Institut de la Statistique Québec. Naissances selon Le lieu de naissance de la mère, PAR région administrative, Québec, 2010-2012. Available: http://www.stat.gouv. qc.ca/docs-hmi/statistiques/population-demographie/naissancefecondite/428ra.htm

30. Statistics Canada. National household survey: data tables, immigration and Ethnocultural diversity, 2011. Available: https:// www12.statcan.gc.ca/nhs-enm/2011/dp-pd/dt-td/Lp-eng.cfm? LANG $=E \& A P A T H=3 \& D E T A I L=0 \& D I M=0 \& F L=A \& F R E E=0 \& G C=$ $0 \& G I D=0 \& G K=0 \& G R P=0 \& P I D=0 \& P R I D=0 \& P T Y P E=105277 \& S=$ 0\&SHOWALL $=0 \& S U B=0 \&$ Temporal $=2013 \&$ THEME $=95 \& \mathrm{VID}=0 \&$ VNAMEE $=\&$ VNAMEF $=$

31. Chapdelaine RSF. The meanings of language transmission: the experiences of migrant mothers living in Saskatoon (dissertation). Saskatoon, Saskatchewan: University of Saskatchewan, 2010.

32. Nguyen XL. The role of parents in maintaining cultural values in Vietnamese immigrant families in Windsor (dissertation). Windsor, Ontario: University of Windsor, 2013.

33. Betts V. Transnational gender, sexuality and identity construction ambivalent subjectivities of Somali refugee women in the GTA (dissertation). Guelph, Ontario: The University of Guelph, 2011.

34. Dewitt BD. "I Swam across all that" an ethnography of Cambodian women's strength (dissertation). Toronto: York University, 2007.
35. Este DC, Tachble AA. The perceptions and experiences of Russian immigrant and Sudanese refugee men as fathers in an urban center in Canada. Ann Am Acad Pol Soc Sci 2009;624:139-55.

36. Fraser N. Guilt Trippin' and the Mothering of black boys in Toronto (dissertation). Toronto: York University, 2011.

37. Tachble AA. Fathering perceptions and experiences of Ethiopian immigrant/refugee men in a Canadian urban centre (dissertation). Calgary, Alberta: University of Calgary, 2011.

38. Anderson L, Hadzibegovic DS, Moseley JM, et al. Household food insecurity shows associations with food intake, social support utilization and dietary change among refugee adult caregivers resettled in the United States. Ecol Food Nutr 2014;53:312-32.

39. Baergen H. Language losing and language keeping in Spanishspeaking families in Ontario: the mothers' perspectives (dissertation). Winnipeg, Manitoba: University of Manitoba, 2007.

40. Carranza ME. Protesting Against Mothers' Surveillance: Salvadorian Mothers and Their Daughters Negotiating Adolescence in a Foreign Context. J Fam Soc Work 2015;18:106-22.

41. Hassan G, Rousseau C. North African and Latin American parents' and adolescents' perceptions of physical discipline and physical abuse: when dysnormativity begets exclusion. Child Welfare 2009;88:5-22.

42. Maiter S, Stalker C. South Asian immigrants' experience of child protection services: are we recognizing strengths and resilience? Child Fam Soc Work 2011;16:138-48.

43. Rousseau C, Ferradji T, Mekki-Berrada A, et al. North African Muslim immigrant families in Canada giving meaning to and coping with the war on terror. J Immigr Refug Stud 2013;11:136-56.

44. Ashbourne LM, Baobaid M, Azizova KS. Expanding Notions of Family Time and Parental Monitoring: Parents' and Adolescents' Experiences of Time Spent Together and Apart in Muslim Immigrant Families. J Comp Fam Stud 2012;43:201-15

45. Carranza ME. Salvadorian ethnic pride: a bridge for reducing mother-daughter conflict due to Acculturation into Canadian Society. Canadian Social Work Review/Revue canadienne de service social 2012;29:61-85.

46. Costigan CL, Koryzma CM. Acculturation and adjustment among immigrant Chinese parents: mediating role of parenting efficacy. $J$ Couns Psychol 2011;58:183-96.

47. Tardif CY, Geva E. The link between Acculturation disparity and conflict among Chinese Canadian immigrant Mother-Adolescent dyads. J Cross Cult Psychol 2006;37:191-211.

48. Zohreh Yaghoub Zadeh, Geva E, Rogers MA. The impact of acculturation on the perception of academic achievement by immigrant mothers and their children. Sch Psychol Int 2008;29:39-70.

49. Chi X. Negotiating two worlds: a cross-cultural narrative of Chinese immigrant parents' encounter with Canadian schooling (dissertation). Toronto: University of Toronto, 2014.

50. Guo Y. Diversity in public education: Acknowledging immigrant parent knowledge. Canadian Journal of Education 2012;35:120-40.

51. Liboy $M-G$, Venet M. Participation of immigrant families at school: perspectives of Congolese parents in Edmonton (Alberta). Journal of International Migration and Integration 2011;12:155-71.

52. Brabant LH, Lapierre S, Damant D, et al. Immigrant children: their experience of violence at school and community in host country. Child Soc 2016;30:241-51

53. Montreuil M, Saint-Laurent O, Carnevale FA. The moral experiences of children living in poverty: a focused ethnography. Journal of Childhood Studies 2017;42.

54. Adair JK. The impact of discrimination on the early schooling experiences of children from immigrant families. Washington DC: Migration Policy Institute, 2015.

55. Berry JW, Vedder P. Adaptation of immigrant children, adolescents and their families. In: Gielen UP, Roopnarine JL, eds. Childhood and adolescence: cross-cultural perspectives and applications. 2nd edition. Santa Barbara, California: Praeger, 2016.

56. Hooper K, Zong J, Capps R, et al. Young children of refugees in the United States: integration successes and challenges. Washington DC: Migration Policy Institute, 2016.

57. Pratt-Johnson Y. Stressors experienced by immigrant and other non-native English-speaking students in U.S. schools and their families. Journal of Social Distress and the Homeless 2015;24:140-50.

58. Zontini E, Reynolds T. Ethnicity, families and social capital: caring relationships across Italian and Caribbean transnational families. International Review of Sociology 2007;17:257-77.

59. Baldassar L. Transnational families and the provision of moral and emotional support: the relationship between truth and distance. Identities 2007:14:385-409. 
60. Merla L. Salvadoran Migrants in Australia: An Analysis of Transnational Families' Capability to Care across Borders. Int Migr 2015;53:153-65.

61. Glick JE. Connecting complex processes: a decade of research on immigrant families. J Marriage Fam 2010;72:498-515.

62. Ukwatta S. Sri Lankan female domestic workers overseas: mothering their children from a distance. J Popul Res 2010;27:107-31.

63. Ryan L, Sales R, Tilki M, et al. Social networks, social support and social capital: the experiences of recent Polish migrants in London. Sociology 2008;42:672-90.

64. Ryan L. Migrant women, social networks and motherhood: the experiences of Irish nurses in Britain. Sociology 2007;41:295-312.

65. Fresnoza-Flot A. Migration status and transnational mothering: the case of Filipino migrants in France. Global Networks 2009;9:252-70.

66. Boccagni P. Practising motherhood at a distance: retention and loss in Ecuadorian transnational families. J Ethn Migr Stud 2012;38:261-77.

67. Marchetti-Mercer MC. Those easily forgotten: the impact of emigration on those left behind. Fam Process 2012;51:376-90.

68. Marchetti-Mercer MC. "If You Uproot a Tree You Leave a Big Hole Behind": Systemic Interconnectedness in Emigration and Family Life. Contemp Fam Ther 2016;38:339-52.

69. Horn V. Cross-border mobility and long-distance communication as modes of care circulation: insights from the Peruvian 'zero generation'. J Ethn Migr Stud 2017;43:303-20.

70. Viruell-Fuentes EA, Schulz AJ. Toward a dynamic conceptualization of social ties and context: implications for understanding immigrant and Latino health. Am J Public Health 2009;99:2167-75.

71. Poeze M, Dankyi EK, Mazzucato V. Navigating transnational childcare relationships: migrant parents and their children's caregivers in the origin country. Global Networks 2017;17:111-29.

72. Urrieta L, Martinez S. Diasporic community knowledge and school absenteeism: Mexican immigrant pueblo parents' and grandparents' Postcolonial ways of educating. Interventions 2011:13:256-77.

73. Tingvold L, Middelthon A-L, Allen J, et al. Parents and children only? Acculturation and the influence of extended family members among Vietnamese refugees. International Journal of Intercultural Relations 2012;36:260-70.

74. Tse C. Satellite babies in transnational families: a study of parents' decision to separate from their infants. Infant Mental Health Journal 2009;30:265-86.

75. de MR, Oliveira G. Transnational care constellations: Mexican immigrant mothers and their children in Mexico and in New York City (dissertation. New York: Columbia University, 2015.

76. Levitt P, Jaworsky BN. Transnational migration studies: past developments and future trends. Annu Rev Sociol 2007;33:129-56.

77. Levitt $P$, Schiller NG. Conceptualizing Simultaneity: a transnational social field perspective on Society1. Int Migr Rev 2004;38:1002-39.

78. Acevedo-Garcia D, Sanchez-Vaznaugh EV, Viruell-Fuentes $E A$, et al. Integrating social epidemiology into immigrant health research: a cross-national framework. Soc Sci Med 2012;75:2060-8.

79. Zimmerman C, Kiss L, Hossain M. Migration and health: a framework for 21st century policy-making. PLoS Med 2011;8:e1001034.

80. Murphy EJ, Mahalingam R. Transnational ties and mental health of Caribbean immigrants. J Immigr Health 2004;6:167-78.

81. Alcántara C, Chen C-N, Alegría M. Transnational ties and past-year major depressive episodes among Latino immigrants. Cultur Divers Ethnic Minor Psychol 2015;21:486-95.

82. Afulani PA, Torres JM, Sudhinaraset M, et al. Transnational ties and the health of sub-Saharan African migrants: the moderating role of gender and family separation. Soc Sci Med 2016;168:63-71.

83. Pannetier J, Lert F, Jauffret Roustide M, et al. Mental health of subSaharan African migrants: the gendered role of migration paths and transnational ties. SSM Popul Health 2017;3:549-57.
84. Falicov CJ. Working with transnational immigrants: expanding meanings of family, community, and culture. Fam Process 2007;46:157-71.

85. Villa-Torres L, González-Vázquez T, Fleming PJ, et al. Transnationalism and health: a systematic literature review on the use of transnationalism in the study of the health practices and behaviors of migrants. Soc Sci Med 2017;183:70-9.

86. Sakamoto I. A critical examination of immigrant acculturation: toward an anti-oppressive social work model with immigrant adults in a pluralistic Society. Br J Soc Work 2007;37:515-35.

87. Stone E, Gomez E, Hotzoglou D, et al. Transnationalism as a motif in family stories. Fam Process 2005;44:381-98.

88. Tiilikainen M, Koehn PH. Transforming the boundaries of health care: insights from Somali migrants. Med Anthropol 2011:30:518-44.

89. Hernández-Plaza S, Alonso-Morillejo E, Pozo-Muñoz C. Social support interventions in migrant populations. Br J Soc Work 2005;36:1151-69.

90. Levitt MJ, Lane JD, Levitt J. Immigration stress, social support, and adjustment in the first postmigration year: an intergenerational analysis. Res Hum Dev 2005;2:159-77.

91. Finch BK, Vega WA. Acculturation stress, social support, and self-rated health among Latinos in California. $J$ Immigr Health 2003;5:109-17.

92. Short KH, Johnston C. Stress, maternal distress, and children's adjustment following immigration: the buffering role of social support. J Consult Clin Psychol 1997;65:494-503.

93. Hernández-plaza S, Pozo C, Alonso-Morillejo E. The role of informal social support in needs assessment: proposal and application of a model to assess immigrants' needs in the South of Spain. $J$ Community Appl Soc Psychol 2004;14:284-98.

94. Dreby J. Children and power in Mexican transnational families. $J$ Marriage Fam 2007;69:1050-64

95. Schmalzbauer L. Searching for wages and mothering from afar: the case of Honduran transnational families. J Marriage Fam 2004;66:1317-31.

96. Baldassar L. Transnational families and aged care: the mobility of care and the migrancy of ageing. J Ethn Migr Stud 2007;33:275-97.

97. Mazzucato V, Schans D. Transnational families and the well-being of children: conceptual and methodological challenges. J Marriage Fam 2011;73:704-12.

98. Barglowski K, Bilecen B, Amelina A. Approaching transnational social protection: methodological challenges and empirical applications. Popul Space Place 2015;21:215-26.

99. Merry L, Mogere D, Odindo D, et al. Transnational family support and perspectives from family members back home: a pilot study in Kisumu, Kenya. Journal of Global Health Reports 2019;3.

100. Knoblauch $\mathrm{H}$. Focused ethnography. Forum qualitative sozialforschung/forum: qualitative social research 2005;6.

101. Cruz EV, Higginbottom G. The use of focused ethnography in nursing research. Nurse Res 2013;20:36-43.

102. Temple B, Edwards R, Alexander C. Grasping at context: cross language qualitative research as secondary qualitative data analysis. Forum Qualitative Sozialforschung/Forum: Qualitative Social Research, 2006.

103. Braun V, Clarke V. Using thematic analysis in psychology. Qual Res Psychol 2006;3:77-101.

104. Alhojailan MI. Thematic analysis: a critical review of its process and evaluation. West East Journal of Social Sciences 2012;1:39-47.

105. Wolf ZR. Ethnography: the method. In: Munhall P, ed. Nursing research: a qualitative perspective. Jones \& Bartlett Learning, 2012.

106. Guba EG. Criteria for assessing the trustworthiness of naturalistic inquiries. ECTJ 1981;29.

107. Shenton AK. Strategies for ensuring trustworthiness in qualitative research projects. Education for Information 2004;22:63-75.

108. Kirk S. Methodological and ethical issues in conducting qualitative research with children and young people: a literature review. Int $J$ Nurs Stud 2007;44:1250-60. 